\title{
Stage III Acral Lentiginous Melanoma AJCC v7
}

National Cancer Institute

\section{Source}

National Cancer Institute. Stage III Acral Lentiginous Melanoma A/CC v7. NCI Thesaurus. Code C8783.

Stage III includes: Any T, N1-3, M0. Stage III is divided into three pathologic subgroups: IIIA, IIIB, and IIIC. There are no clinical subgroups for stage III. N1: Cutaneous melanoma with metastasis in one regional lymph node. N2: Cutaneous melanoma with metastases in 2-3 regional lymph nodes or in transit met(s)/satellite(s) without metastatic nodes. N3: Cutaneous melanoma with 4 or more metastatic nodes, or matted nodes, or in transit met(s)/satellite(s) with metastatic node(s). M0: No detectable evidence of distant metastases. (from AJCC 7th Ed.) 